Skidmore College

Creative Matter

Sociology Senior Seminar Papers

Sociology

$5-2019$

\title{
C's Get Degrees and Degrees lead too...Healthier Mental Health? The Effect of Cultural and Social Capital on Mental Health
}

Samantha Garcia

Skidmore College, sgarcia@skidmore.edu

Follow this and additional works at: https://creativematter.skidmore.edu/socio_stu_stu_schol

Part of the Race and Ethnicity Commons

\section{Recommended Citation}

Garcia, Samantha, "C's Get Degrees and Degrees lead too...Healthier Mental Health? The Effect of Cultural and Social Capital on Mental Health" (2019). Sociology Senior Seminar Papers. 19.

https://creativematter.skidmore.edu/socio_stu_stu_schol/19

This Thesis is brought to you for free and open access by the Sociology at Creative Matter. It has been accepted for inclusion in Sociology Senior Seminar Papers by an authorized administrator of Creative Matter. For more information, please contact dseiler@skidmore.edu. 
C's Get Degrees and Degrees lead too...Healthier Mental Health? The Effect of Cultural and Social Capital on Mental Health*

Samantha M. Garcia

Skidmore College

Word Count $=5377$

*Please direct all correspondence to Samantha Garcia, 815 North Broadway, Saratoga Springs, NY 12866. Email: sgarcia@skidmore.edu Special thanks to Jiebei Luo, senior seminar colleagues, Professor Catherine Berheide and Professor Andrew Lindner. 


\section{C's Get Degrees and Degrees lead too... Healthier Mental Health? The Effect of Cultural and Social Capital on Mental Health}

Does social and cultural capital have beneficial outcomes that extend to the mental wellbeing of First Generation College graduates? Obtaining higher levels of educational degrees is known to produce positive rewards in lifestyle, opportunities, and income. Educational mobility is directly linked to social mobility. As one climbs the social ladder, one builds a broader network of people to rely on. This study analyzes 2010-2014 General Social Survey (GSS) data to report on the relationship between first-generation graduate status and self-reported days of mental health among 1654 non-institutionalized respondents in the U.S. All the parents of the respondents in the subset did not have a college degree of any kind. I hypothesize that among individuals whose parents do not have a college degree, first-generation college graduates (FGCG) are more likely to report less days of poor mental health than respondents with no college degree. The results support the hypothesis. Being a FGCG decreases the amount of days of poor mental well-being. In this study I make the connection that acquiring social and cultural capital is an effect of FGCG status. However, age appears to have a significant effect on the number of days of poor mental health, as well. I suggest reasons for this finding in the discussion. 


\section{Cs Get Degrees and Degrees lead too... Healthier Mental Health? The Effect of Cultural and Social Capital on Mental Health}

The prevalence of psychological well-being and resilience, defined in this paper as mental health, within society has become a salient concern. The term "self-care" rarely goes unnoticed in conversations, media advertisements, and institutional discourse on how to improve the experiences of college students. The forms of self-care range from CVS brand face masks to formal accountability study sessions with the dean of students, as personally witnessed at Skidmore College. Self-care in its original form is conscious acts of resistance against institutions and situations that harm one's well-being; be it a toxic family member or finding coping mechanisms against consistent micro-aggressions in a predominantly white institution (PWI). Our understanding of mental health among diverse social groups could be better understood by focusing on the social interactions and situations driving differences among their experiences. Comprehending mental health within minority populations, specifically FGCGs, can be strengthened by focusing on the social and cultural capital they acquire as they transgress through higher educational institutions. The participation in a cultural membership attached to higher education can be beneficial attributes to their success beyond college. This interest derives from literature that discuss the structural inequalities and lack of resources which effect the well-being of FGCG, who are often students of color and/or minority status. This paper seeks to test if social capital, measured as FGCG, is a predictor of ameliorated mental health beyond college. 


\section{LITERATURE REVIEW}

There are significant gaps in literature and research that link together the social resources available to first-generation students and how this specifically effects their mental health. Social psychologist and sociologist either discuss the resources, advantages and disadvantages of low-income families, or health related drawbacks because of their socio-economic status (SES), yet never quite both in one.

First-generation students are often resilient and well-rounded. The number of parents with college degrees has shown a steady increase since the 1980s. According to Cahalan, Ingels, Burns, Planty and Daniel (2006) in the 1980s 77 percent of parents of high school students had not enrolled in a higher education, by 2002 the percent declined to 62 percent. More parents have completed college degrees, opening the passage to college for their children (Cataldi, Bennett and Chen 2018). In the present day, education has become a form of socialization, priming students to engage with curriculum meanwhile learning the social norms necessary to move forward and become active citizens in the economy (Meyer 1977; Apple 2006). Many scholars have argued for and against the purpose of education in society, claiming that it is a streamline of beneficial structures for the wealthy and well-connected often white family, leaving many students of low-income families and of multiple ethnicities and races disadvantaged (Collins 1971; Crosnoe 2004).

In its effect higher education has become a class gateway, an expensive price to pay for students whose parents cannot afford college tuition. Despite the growing efforts of colleges and universities to provide financial aid to students, many students whose 
parents have not gone to college do not attend college or end up dropping out of four year institutions (Cataldi et al 2017; Lehmann 2007). Parents, because of their education experiences are able to pass down valuable information related to their social classes to their children (Crosnoe 2004; Walsemann, Gee, and Geronimus 2009). In other words, educational mobility leads to social mobility. Getting their foot in the door is the hardest of many steps to graduation for first-generation students. According to the National Center for Education statistics, by 201233 percent of first generation high school students enrolled in a public or private four-year institution compared to 68 percent of high school students whose parents earned a bachelor's degree.

Once in the door, many of the reasons for college attrition among first generation students, beyond the burgeoning financial strain, fall mainly on the cultural experiences of such students. Feeling out of place or unable to navigate higher education institutions have negative effects on academic achievement and consequently mental well-being (Corona et al. 2017; Stephens 2012). Health inequalities, such as poor mental health, are persistent among low-income individuals because of a lack of resources and a lack of social groups that encourage healthier lifestyle decisions (Pinxten \& Lievens 2014; Barrett \& Turner 2005; Walsemann et al. 2009).

Among first generation graduates, specifically Latinx students, higher education places unique cultural stressors on them which negatively impact their academic performance (Corona et al. 2016). Vega and Rumbaut (1991) highlight that the common belief was that within Latinx communities' strong family connections were able to buffer the negative effect of immigrant migration and culture shock. Various other studies 
dispute this point, claiming that the assimilation into American society proves quite difficult (ten Kate et al. 2017; Montazer and Wheaton 2011). First generation students feel a heightened sense of isolation, stress, and guilt from being distant from their families and the pressure to outperform the negative stereotypes placed on them (Rondini 2015; Stephens 2012; Lehmann 2007). These symptoms ring especially true to first generation students of Latinx descent (Corona 2016; Feliciano 2006; Stephens 2012; Rondini 2015).

The break of intergenerational cycles requires discipline, support from parents, and rigorous high school transcripts. Throughout the college careers of first-generation students, parents seek to make up for their lack of opportunities through the success of their children (Gofen 2009; Rondini 2015). The pressure is on first generation students to excel in college. A key component to this success is their ability to navigate and assimilate into the dominant culture at four year institutions. Higher education requires a degree of cultural and social knowledge, which is associated with middle and upper class America. The cultural capital of middle class America is not readily accessible in the homes of students from low-income families, therefore they must acquire this knowledge elsewhere. It is here where cultural capital and a degree of social capital play key roles in the well-being of first generation students.

To navigate new environments that requires learning a new cultural language is challenging, yet finding space within the institution, making experiences form into a wellconnected environment of supportive individuals, may make FGCG experiences beyond college less taxing on their well-being. FGCG may experience fewer mental health days after graduation because they will have learned how to create a well-connected networks 
of peers within higher education that will uplift them through the rough period in colleges and open doors to new possibilities beyond college (Gofen 2009; Crul, Jens, Elif, and Frans 2017). Therefore, I hypothesize that first-generation college graduates are more likely to report fewer days of poor mental health, attributed to the fact they may experience less challenges and better opportunities once they acquire more social and cultural capital.

\section{THEORITICAL FRAMEWORK}

\section{Cultural Capital}

Within Pierre Bourdieu's theory of cultural capital, college is the institutionalized state of cultural markers, offering legitimate recognition to individuals who have gained a postsecondary degree. In its principal form cultural capital can only be successfully passed on if the parents and family members possess cultural capital. In this continuous process the children of well-cultured families have immediate access to their knowledge and wealth (Bourdieu 1986). The consistent and defined traditions and values are not only surrounding the children but a part of the children. Higher education institutions act as another stepping stone into higher social classes, it is easier for cultured students to do well academically and socially. First-generation students face a cultural barrier when first introduced to higher education. They quickly have to learn and acquire the norms and values of the institution to be successful (Gofen 2009). However, cultural capital can be acquired, since cultural capital is not an ascription but an active participation in a culture (DiMaggio 1982). Bourdieu recognized this briefly in his claim that academic qualifications are a fast track to cultural capital, which to the extent individuals participate 
MENTAL HEALTH AND FIRST GENERATION GRADUATES

and engage with academia grants them the institutional recognition which can be later converted into economic capital. It is for this reason that it is hypothesized first generation graduates will have fewer poor mental health days.

\section{Social Capital}

Social capital theory asserts that the beneficial resources, such as social networks, family ties, and institutional connections are maintained and reinforced by individuals or groups through consistent participation (Bourdieu 1986, Coleman 1988). Social capital is efficient and productive when it extends beyond the single person and becomes strengthened through word of mouth. As a result, strong positive networks become extendable to those not immediately related. First generation graduates may come out of college informed and connected to a network of peers and professionals. The addition to such resources in their lives lead to healthier lifestyle options because they are now able to lean on a support network of people and have better access to healthcare. (Crul et al. 2017).

Bourdieu (1986) in his theory of social capital asserts that a strong network of individuals and groups is a valuable resource when recognized and institutionalized. Over time these reliable connections can lead to positive benefits for all parties maintaining the status of their network. Social capital is often used to explain why the children of parents who use their social capital to enroll their children in prestigious boarding schools and colleges are more successful in school and beyond (Apple 2006). Parents who did not complete a college degree, may lack social ties that help give their children access to supportive social circles (Gofen 2009, Crosnoe 2004). The access to well-connected 
groups can later be drawn on by the students themselves to help them within higher education institutions (Coleman 1988).

First generation graduates, can ameliorate their lack of social capital by fortifying their sense of moral advantage and taking advantage of the new opportunities for upward mobility (Lehmann 2009) as seen among low-income immigrant students (Crul et al. 2017). Han (2016) suggests that positive interactions and links in community produce positive benefits, specifically higher self-esteem. Therefore, among individuals whose parents do not have a college degree, first-generation college graduates (FGCG) are more likely to report less days of poor mental health than respondents with no college degree.

\section{METHODS}

Data

To study the effect of first-generation college graduate status on mental health this study used the 2010-2014 General Social Survey (GSS) (Smith, Davern, Freese, and Hout) a nationally representative random sample of non-institutionalized 18 year olds and older because the poor mental health question was asked during those specific years. For more information on the data set visit, http://gss.norc.org/.

Of the 6556 individuals originally sampled between the years 2010 and 2014 in the GSS, only half $(\mathrm{N}=3531)$ were asked the mental health question. From the original sample a subset of individuals, who would be first generation graduates, was created by filtering for both mother and father's degree being less than community college, leaving the 
sample population used in this study at $\mathrm{N}=1654$. Prior to working with the subset, the missing data for each variable used was individually deleted.

First generation student status was operationalized by using the varaible for highest degree of education completed by both of the respondent's parents (madeg and padeg). The lowest being less than a high school diploma and the highest being a graduate's degree. Mental health was measured with the self-reported poor mental health variable (mnthlth). This variable is helpful when taking into consideration individuals who are reluctant to claim depression or anxiety as a problem or have not defined their experiences as relating to one or both disorders. The poor mental health variable asked respondents "Now thinking about your mental health, which includes stress, depression, and problems with emotions, for how many days during the past 30 days was your mental health not good?" The answer categories were on a scale from 0 to 30 days.

To further identify college graduates and non-college graduates, a dummy variable was created in order to distinguish between respondents who had completed a college degree and those who had not. Using the respondent's degree variable (degree) which asks respondents to choose between a range of categories, starting with the lowest being less than a high school diploma and the highest being a graduate's degree. This variable was simplified into two categories: $0=$ no college degree (less than high school through high school) and 1 = first generation graduate (junior college through a graduate degree). The respondents' age, sex, race, and ethnicity were controlled for. Dummy variables were created for all the control variables except for age. The variables were recoded as such. For sex, $1=$ female and $0=$ male. For race, $1=$ non-white and $0=$ white. For ethnicity, 1 
$=$ Hispanic and $0=$ non-Hispanic. The following sections describe the relationships found between the variables.

\section{FINDINGS}

Univariate Analysis

\section{${ }^{* *}$ Table 1 about here ${ }^{* *}$}

Table 1 reports the means and standard deviations of all the variables used in this study. The average days of poor mental health were 4 days. 86 percent of the respondents fell between 0 and 5 days. The deviation in these numbers reported up to a 7-day difference. More than half of respondents, 58 percent reported, zero days. Only 14 percent of the respondents said they experienced between a week or up to a month of poor mental health days.

${ }^{\star *}$ Figure 1 about here ${ }^{* *}$

First generation graduates made up 34 percent of the sample. The majority of respondents, 66 percent, did not go to college like their parents. There was a deviation of 47 percent in this finding. Figure 2 shows the difference between FGCG and Non-college graduates.

\section{${ }^{* *}$ Figure 2 about here ${ }^{* *}$}

The average race of the respondents in this sample were 78 percent white, with a standard deviation of 41 percent. Only 22 percent of the people in this study were people of color, as seen in Figure 3.18 percent of the people of color identified as Hispanic, with a standard deviation of 38 percent. Figures 3 and 4 show the visual composition of these demographics. 
MENTAL HEALTH AND FIRST GENERATION GRADUATES

${ }^{* *}$ Figure 3 about here ${ }^{* *}$

${ }^{* *}$ Figure 4 about here ${ }^{* *}$

Figure 5 tells us the gender composition of this study. Like the demographic makeup of the country, respondents were split almost in half, with the 52 percent of the sample being women and 48 percent being men.

${ }^{* *}$ Figure 5 about here ${ }^{* *}$

${ }^{* *}$ Figure 6 about here ${ }^{* *}$

On average the age of a respondent was 46 years old, with the majority of population falling between 32 and 70 years of age. Figure 6 reveals a graph that is slight skewed to the left. 62 percent of respondents in this sample were 50 years or younger. Taking into consideration these findings, the overall picture suggests that the average sample of people in this study are non-Hispanic white women in their 40 s without a college degree.

Bivariate Analysis

\section{${ }^{* *}$ Table 2 about here ${ }^{\star *}$}

In the bivariate analysis a more detailed picture of the relationships between poor mental health and college degree is described. Table 2 suggests that being a first generation graduate has a significant negative effect on self-reported poor mental health days, which in this case suggests a positive outcome since there is a decrease in poor mental health days $(r=-.079)$. Age although a weak relationship, $(r=-.094)$ has a significant effect on poor mental health. This means that the older the respondent is the fewer days of poor mental health they report having. In line with these results, age and 
MENTAL HEALTH AND FIRST GENERATION GRADUATES

first generation graduates have a significant relationship with one another $(r=.094)$. This finding is consistent with American trends of older age groups being the first in their families to complete a college degree. It is likely that the older a respondent is the more likely they are to be the first in their families to have a college degree. Therefore, it is also likely that first generation graduates report fewer mental health days because they are older respondents.

Interestingly, Table 2 suggests that first generation college graduates are more likely not to be of a Hispanic ethnicity $(r=-.177)$. This may in part be explained by the accessibility of white respondents being the first to go to college. This goes hand in hand with the discrimination people of color experienced during the widespread rise in the popularity of receiving a college education after WWII. In line with the previous findings of ethnicity and first generation graduates, the older the respondent is the more likely that they are not Hispanic $(r=-.218)$, which may also signify that the younger population in the United States is increasingly Hispanic. Table 2 does show a relationship between people of color and an identification of a Hispanic ethnicity $(r=.213)$. However, the unexpected yet interesting finding in Table 2 is the negative correlation between Hispanic respondents and women. If the respondent is of a Hispanic ethnicity they are more likely to be a man than a woman $(r=-.074)$.

\section{Multivariate Findings}

\section{${ }^{* \star}$ Table 3 about here ${ }^{* *}$}

Table 3 shows us that 1.9 percent of the variance in mental health is explained by first generation graduate status, race, ethnicity, gender, and age. The F-test signifies that 
the outcomes are significant and the hypothesis in question is supported by the results. These findings suggest age and first generation respondents were the two prominent variables to have a significant decrease in reported poor mental health days at the .01 significance level. For every year older a respondent is, the more likely they are to report a decrease in poor mental health days, noted with the largest standardized coefficient of -.098 in Table 3.

$$
Y=6.214 x_{1}-1.219 x_{2}-.367 x_{3}-.802 x_{4}+.646 x_{5}-.05 x_{6}
$$

Using the regression equation shown above, the statistics tell a different story for different individuals relative to the 6 days reported as the constant in Table 3. A 45-yearold FGCG Hispanic women of color is more likely to report two poor mental health days fewer. In comparison, a 45-year-old white man who is not a college graduate is more likely to report 4 poor mental health days fewer. If the man had gone to college, he may have reported 3 days fewer. The single day difference is in line with the general results reported in Table 2 between FGCG and poor mental health.

\section{DISCUSSION}

The results of this study were not completely in line with previous literature. The baseline in this study were people who because of their parents did not have the participation within social and cultural capital memberships to navigate college with more ease. The literature focused on first-generation students being mostly people of Hispanic and Black identity. Although the respondents came from similar education backgrounds, most of the people in this study were older women, most of which did not obtain a college degree, following similar education attainments as their parents. A leading explanation for the demographic may be the increase of women seeking and completing college 
degrees at a higher rate than men, consistent with the literature on gender differences and college completion.

In contrast to the literature, results from Table 3 indicates that being a person of color, a woman, or of Hispanic ethnicity does not bare significantly one's mental health. The lack of significance is an interesting finding after considering the literature on the prevalence of health issues among communities of low-income people of color. Since only 1.9 percent of the variance in mental health is explained by these factors, it's safer to assume that FGCG status is not an exhaustive explanation and there are other factors playing into the mental health of respondents not taken into consideration, although, being a FGCG does indicate a shift in one's mental health.

Age was a significant predictor of fewer mental health days. The older a respondent was the fewer poor mental health days they reported. However, this could be caused by the age demographic of the sample. The majority of sample were $40-50$ year olds, at such a point in their lives the amount of stress they experience could be decreasing, leading to fewer poor mental health days.

However, the implications of this study point towards positive changes that can be made in communities of color and among people who second-guess a college degree. Often stories of success and wealth are what follow college graduations. These stories should not be disregarded. It is in the process of achieving those success stories and moving forward that FCGCs become discouraged. As it is reiterated consistently in literature, it is the students who are not traditionally on the college pathway that are the highest risk of college attrition (Lehman 2009). Extensive support from family members may get FGCG through the collegiate door, but it is up to them to compensate for the lack 
of familiarity with rigorous course-loads, office hours, and professional personal relationships with peers that academia asks of them (Gofen 2009; Lehman 2009; Rondini 2016). Despite the findings suggesting the image of a first-generation college student being an older white woman, the new image we are seeing is one of a young woman of color. This is the image that should be kept in mind as we move forward with our future research. The process of going to college, feeling like an imposter at times, or simply feeling out of place, are only momentary obstacles in the bigger picture. These results suggest that the outcomes outweigh the challenges. We should continue to encourage young women and men of color to pursue college degrees. Not only are the findings statistically significant, but they are potential success stories on the personal level that have the influence to inspire others among FCGC families and peers. FGCG after learning the cultural markers of higher education are now equipped with the tools and skills necessary to pass onto those coming along behind them to help new first-generation college students pass through those obstacles with more ease.

Social capital are the resources of people and networks that provide a support system to us (Bourdieu 1986; Coleman 1988; Crul et al. 2017). College in addition the immediate educational benefits, functions as a gateway into a world of well-connected people and businesses. Access to such a wealth of connections, as Bourdieu and Coleman assert, must have positive impacts in our lives. The phrase "it takes a village" rings true for most of the college experience.

CONCLUSION 
This study looked to answer whether among individuals whose parents do not have a college degree, were first-generation college graduates (FGCG) are more likely to report less days of poor mental health than respondents with no college degree. Analyzing a small sample of 1654 non-institutionalized individuals from 2010-2014 GSS data showed that taking the next step and completing a college degree does bear significantly on ameliorating poor mental health days. Therefore, the hypothesis was supported. People who continue into college report one fewer day of poor mental health in comparison to those who do not complete a college degree. However, intricacies in this hypothesis was illuminated through the demographic composition of the individuals in the study. The sample consisted mostly of older white women, although the sample revealed an unexpected demographic, the results remain significant and hold important implications for future research.

The findings are positive in multiple aspects. More than half of the sampled population reported very few days of poor mental health, between zero and five days. This is a positive outlook; it would be unfortunate if the majority of the sample experienced numerous days of poor mental health. However, poor mental health being a self-reported variable may skew the reality of how these people realistically feel. In looking towards further understandings on how mental health affects the population this study opens up a space for future research. Controlling for specific demographics, how do young woman of color fair with feelings of anxiety, depression, or stress after college. Does climbing the social ladder look and feel different for them than the older white women in this study? There is still plenty of space and possibilities to continue to understand what positively and negatively affects FGCGs well-being. 
As with any preliminary research, the limitations to this study are a few aspects not included in this study. Income may be a greater predictor of mental health among the FGCG population. Future research should continue to improve on this topic by including income or another value of socio-economic status. Perhaps by even looking at this topic in a new light, to investigate whether FGCG status mediates the relationship between education and income. Another crucial component to this research is a sophisticated measure of social networks and friendships, which could strengthen and clarify the results.

Initially, this project was carried out with the intention to study younger groups of individuals who identify as first generation college graduates. Along with previous suggestions, future research should target a specific groups of younger individuals who identify as First Generation College graduates to better understand their experiences. This case for this being that the younger population of the United States is made of more Black and Hispanic individuals. The sociological implications of this study are optimistic, yet never the less straight-forward. A college degree can go a long way for populations with few educational attainments. Educational mobility is social mobility in the United States. Whether success is measured as income, socio-economic status, or mental wellbeing, the children of parents with no college degree should be encouraged to pursue a degree, as it yields positive results beyond the momentary challenges of college. 


\section{REFERENCES}

Apple, Michael. 2006. "Whose Markets, Whose Knowledge." Pp. 257-273 in Sociology of Education. $3^{\text {rd }}$ Ed. A Critical Reader, edited by A.R. Sadovnik and R. W. Coughlan. New York: Routledge.

Barrett, Anne E.and R. J. Turner. 2005. "Family Structure and Mental Health: The Mediating Effects of Socioeconomic Status, Family Process, and Social Stress." Journal of Health \& Social Behavior 46(2):156-169.

Bourdieu, Pierre. 1986. "The Forms of Capital." Pp.83-95 in Sociology of Education. $3^{\text {rd }}$ Ed. A Critical Reader, edited by A.R. Sadovnik and R. W. Coughlan. New York: Routledge.

Cahalan, Margaret W., Steven J. Ingels., Laura J. Burns., Michael Planty and Bruce Daniel. 2006. “United States High School Sophomores: A Twenty-Two Year Comparison, 1980-2002. U.S. Department of Education." Washington, DC: National Center for Education Statistics.

Cataldi, Emily F., Bennett, Christopher and Chen, Xianglei. 2018. "First-Generation Students: College Access, Presistence, and Postbachelor's Outcomes. Stats in Brief. NCES 2018-421." Washington, DC: National Center for Education Statistics.

Coleman, James S. 1988. "Social Capital in the Creation of Human Capital." Pp.97-113 in Sociology of Education. $3^{\text {rd }}$ Ed. A Critical Reader, edited by A.R. Sadovnik and R. W. Coughlan. New York: Routledge. 
Collins, Randall. 1971. "Functional and Conflict Theories of Education Stratification." Pp.37-51 in Sociology of Education. $3^{\text {rd }}$ Ed. A Critical Reader, edited by A.R. Sadovnik and R. W. Coughlan. New York: Routledge.

Corona, Rosalie, Vivian M. Rodríguez, Shelby E. McDonald, Efren Velazquez, Adriana Rodríguez and Vanessa E. Fuentes. 2017. "Associations between Cultural Stressors, Cultural Values, and Latina/o College Students' Mental Health." Journal of Youth and Adolescence 46(1):63-77.

Covarrubias, Rebecca, Andrea Romero and Michael Trivelli. 2015. "Family Achievement Guilt and Mental Well-being of College Students." Journal of Child \& Family Studies 24(7):2031-2037.

Crosnoe, Robert. 2004. "Social Capital and the Interplay of Families and Schools." Journal of Marriage \& Family 66(2):267-280.

Crul, Maurice, Jens Schneider, Elif Keskiner and Frans Lelie. 2017. "The Multiplier Effect: How the Accumulation of Cultural and Social Capital Explains Steep Upward Social Mobility of Children of Low-Educated Immigrants." Ethnic \& Racial Studies 40(2):321-338.

DiMaggio, Paul. 1982. "Cultural Capital and School Success: The Impact of Status Culture Participation on the Grades of U.S. High School Students." American Sociological Review 47(2):189-201. 
MENTAL HEALTH AND FIRST GENERATION GRADUATES

Feliciano, Cynthia. 2006. "Beyond the Family: The Influence of Premigration Group Status on the Educational Expectations of Immigrants' Children." Sociology of Education 79(4):281-303.

Gofen, Anat. 2009. "Family Capital: How First-Generation Higher Education Students Break the Intergenerational Cycle." Family Relations 58(1):104-120.

Han, Sehee. 2016. "The Association of Self-Esteem with Individual and Contextual Levels of Social Capital: Evidence from a Multilevel Analysis." Social Science Quarterly (Wiley-Blackwell) 97(5):1315-1329.

Harding, Jessica F., Pamela A. Morris and Diane Hughes. 2015. "The Relationship between Maternal Education and Children's Academic Outcomes: A Theoretical Framework." Journal of Marriage \& Family 77(1):60-76.

Lehmann, Wolfgang. 2009. "Becoming Middle Class: How Working-Class University Students Draw and Transgress Moral Class Boundaries." Sociology 43(4):631-647.

Meyer, John W. 1977. "The Effects of Education as an Institution." Pp. 133-149 in Sociology of Education. $3^{\text {rd }}$ Ed. A Critical Reader, edited by A.R. Sadovnik and R. W. Coughlan. New York: Routledge.

Montazer, Shirin, and Blair Wheaton. 2011. "The Impact of Generation and Country of Origin on the Mental Health of Children of Immigrants." Journal of Health and Social Behavior 52 (1):23-42.

Pinxten, Wouter, and John Lievens. 2014. "The Importance of Economic, Social and Cultural Capital in Understanding Health Inequalities: Using a Bourdieu-Based 
Approach in Research on Physical and Mental Health Perceptions." Sociology of Health \& IIIness 36(7):1095-1110.

Rondini, Ashley C. 2016. "Healing the Hidden Injuries of Class? Redemption Narratives, Aspirational Proxies, and Parents of Low-Income, First-Generation College Students." Sociological Forum 31(1):96-116.

Smith, Tom W., Davern, Michael, Freese, Jeremy, and Hout, Michael. 1972-2016. General Social Surveys. Chicago: NORC at the University of Chicago.

ten Kate, Josje, Willem de Koster and Jeroen van der Waal. 2017. "Why Are Depressive Symptoms More Prevalent among the Less Educated? The Relevance of Low Cultural Capital and Cultural Entitlement." Sociological Spectrum 37(2):63-76.

Vega, William A., and Rubén G. Rumbaut. 1991. "Ethnic Minorities and Mental Health." Annual Review of Sociology 17:351-383.

Walseman, Katrina M., Gilbert C. Gee and Arline T. Geronimus. 2009. "Ethnic Differences in Trajectories of Depressive Symptoms: Disadvantage in Family Background, High School Experiences, and Adult Characteristics." Journal of Health and Social Behavior 50:82-98. 
MENTAL HEALTH AND FIRST GENERATION GRADUATES

Table 1. Means, Medians, and Standard Deviations for Variables $(N=1654)$

\begin{tabular}{lccc}
\hline \multicolumn{1}{c}{ Variable } & Mean & Median & SD \\
\hline Poor Mental Health Days & 3.60 & .00 & 7.066 \\
First Generation Graduates & .34 & .00 & .474 \\
People of Color & .22 & .00 & .412 \\
Hispanic & .18 & .00 & .384 \\
Women & .52 & 1.00 & .500 \\
Age & 46.16 & 47.00 & 13.854 \\
\hline
\end{tabular}


Table 2. Correlations $(r)$ between Days of Poor Mental Health and five variables. (Listwise deletion, two-tailed test, $N=1654$ )

\begin{tabular}{|c|c|c|c|c|c|}
\hline Variable & $\begin{array}{c}\text { First } \\
\text { Generation } \\
\text { Graduates }\end{array}$ & Age & Race & Hispanic & Sex \\
\hline $\begin{array}{l}\text { Days of Poor } \\
\text { Mental Health }\end{array}$ & $-.079 * *$ & $-.094^{* *}$ & -.013 & -.016 & .044 \\
\hline $\begin{array}{l}\text { First Generation } \\
\text { Graduates }\end{array}$ & & $.094^{\star *}$ & -.051 & $-.177^{\star \star}$ & .060 \\
\hline Age & & & $-.124^{\star \star}$ & $-.218^{\star *}$ & -.008 \\
\hline Race & & & & $.213^{\star \star}$ & .029 \\
\hline Hispanic & & & & & $-.074^{* *}$ \\
\hline
\end{tabular}

${ }^{* *} \mathrm{p}<.01$ 
MENTAL HEALTH AND FIRST GENERATION GRADUATES

Table 3. Regression of Mental Health on All Variables $(N=1654)$

\begin{tabular}{lcc}
\hline & $\mathrm{b}$ & $\beta$ \\
\hline First Generation Graduates & $-1.219^{\star \star}$ & $-.082^{\star \star}$ \\
People of Color & -.367 & -.021 \\
Hispanic & -.802 & -.044 \\
Women & .646 & .046 \\
Age & $-.050^{\star \star}$ & $-.098^{\star \star}$ \\
Constant & 6.214 & \\
\hline
\end{tabular}

$R^{2}=.019 F(5,1653)=6.299^{*} ; p<.01^{*}$ $p<.01^{* *}$ 
MENTAL HEALTH AND FIRST GENERATION GRADUATES

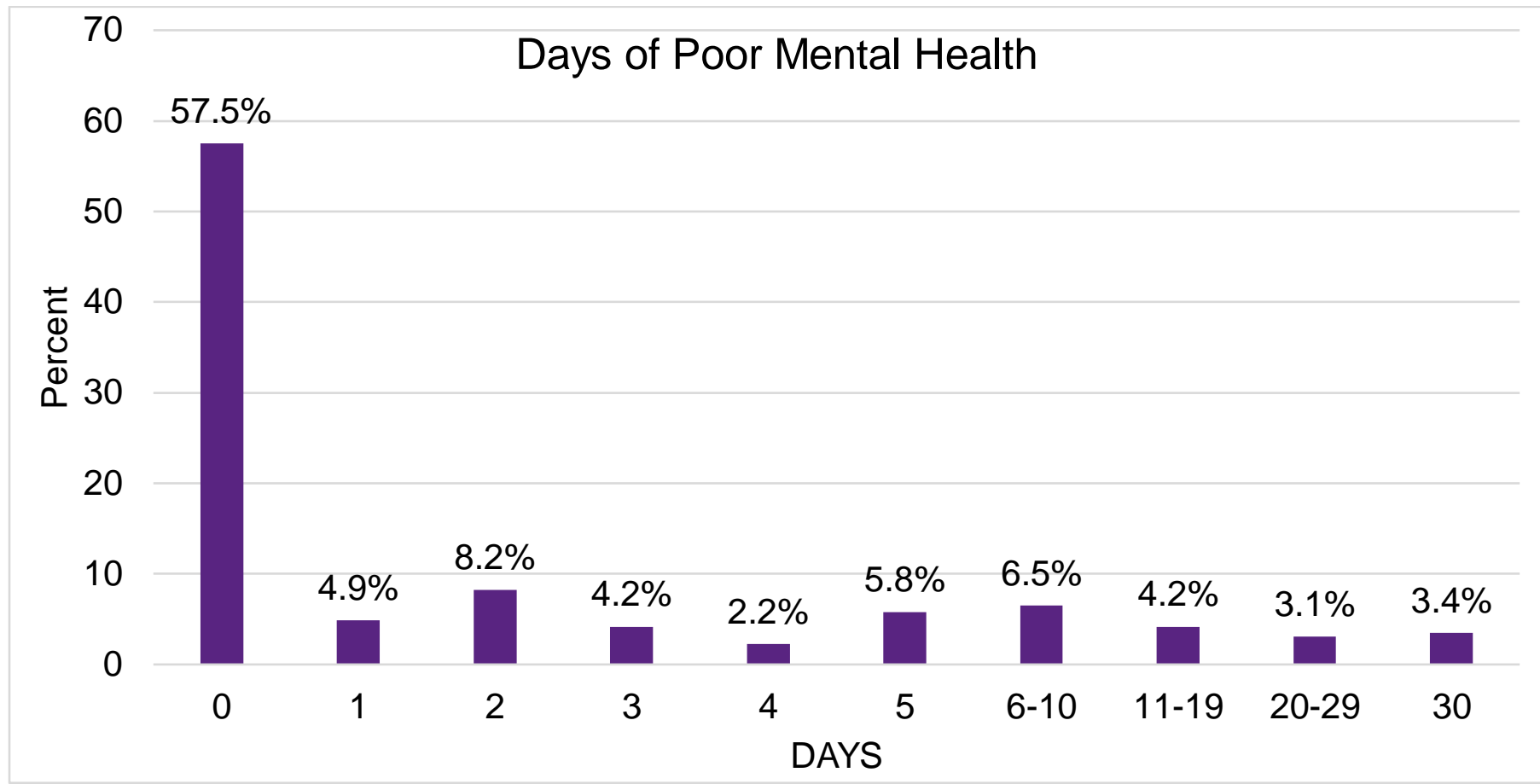

Figure 1. Frequencies for Poor Mental Health Days 


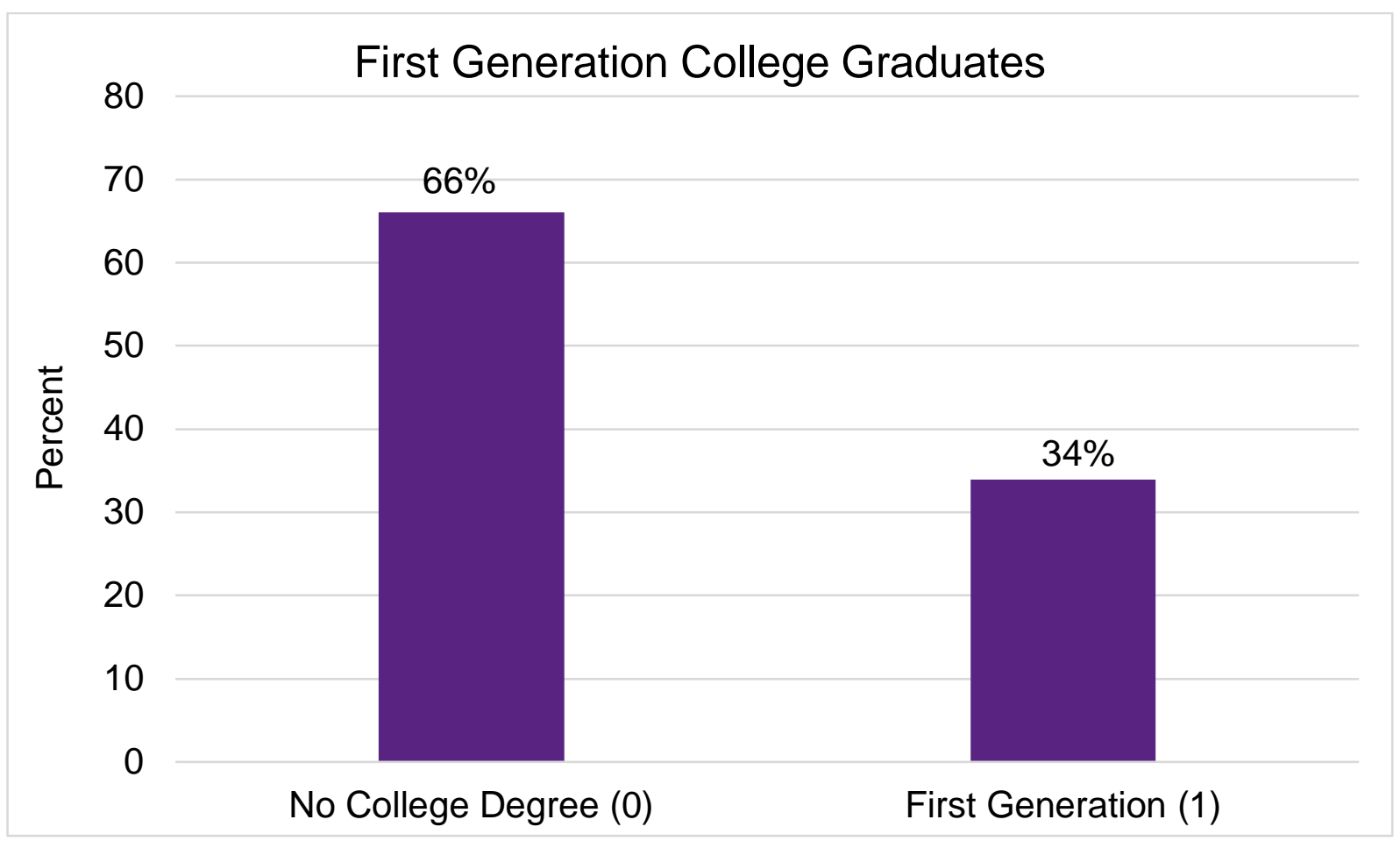

Figure 2. Frequencies for Generation Graduates 


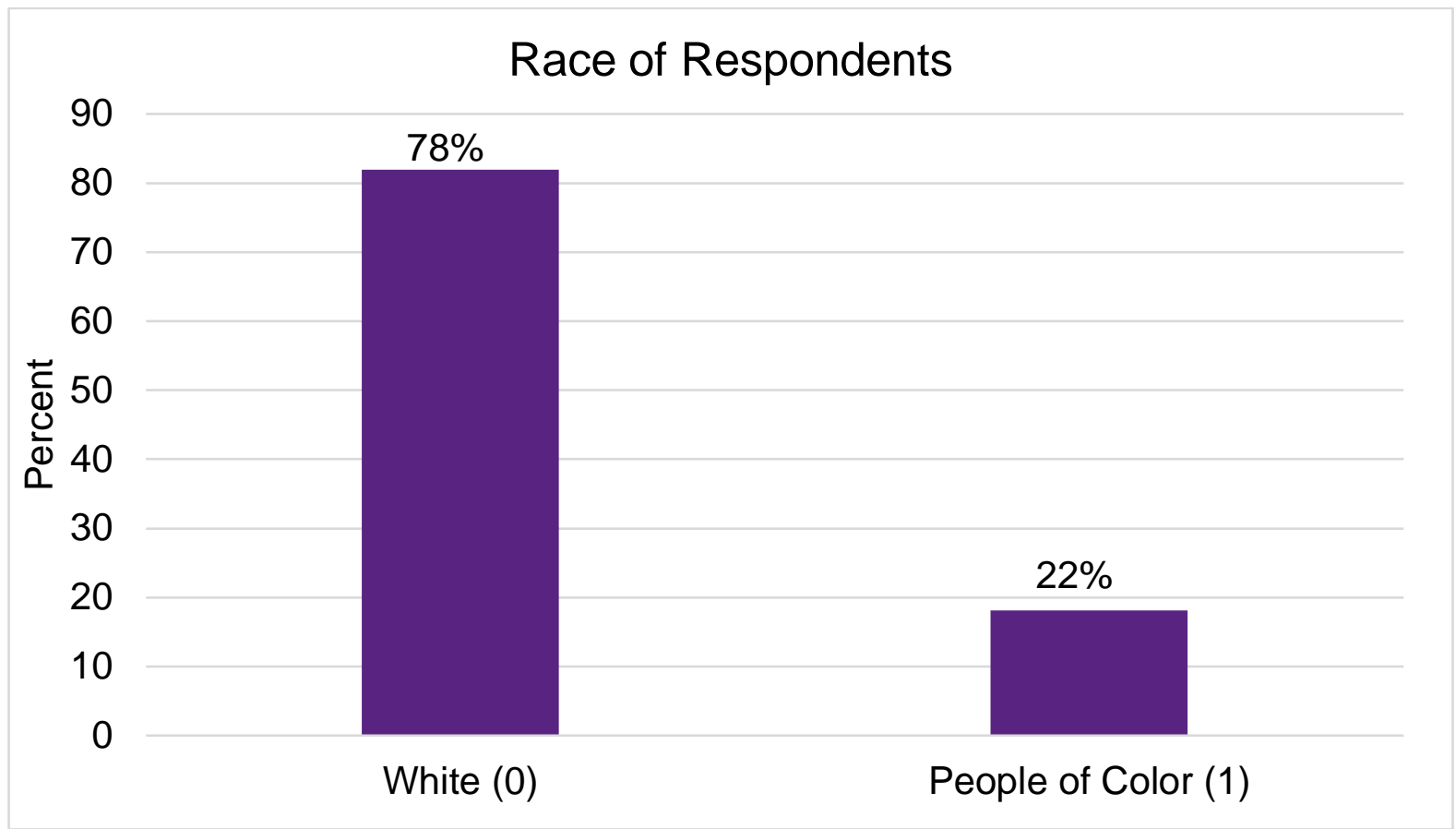

Figure 3. Frequencies for Race of Respondents 
MENTAL HEALTH AND FIRST GENERATION GRADUATES

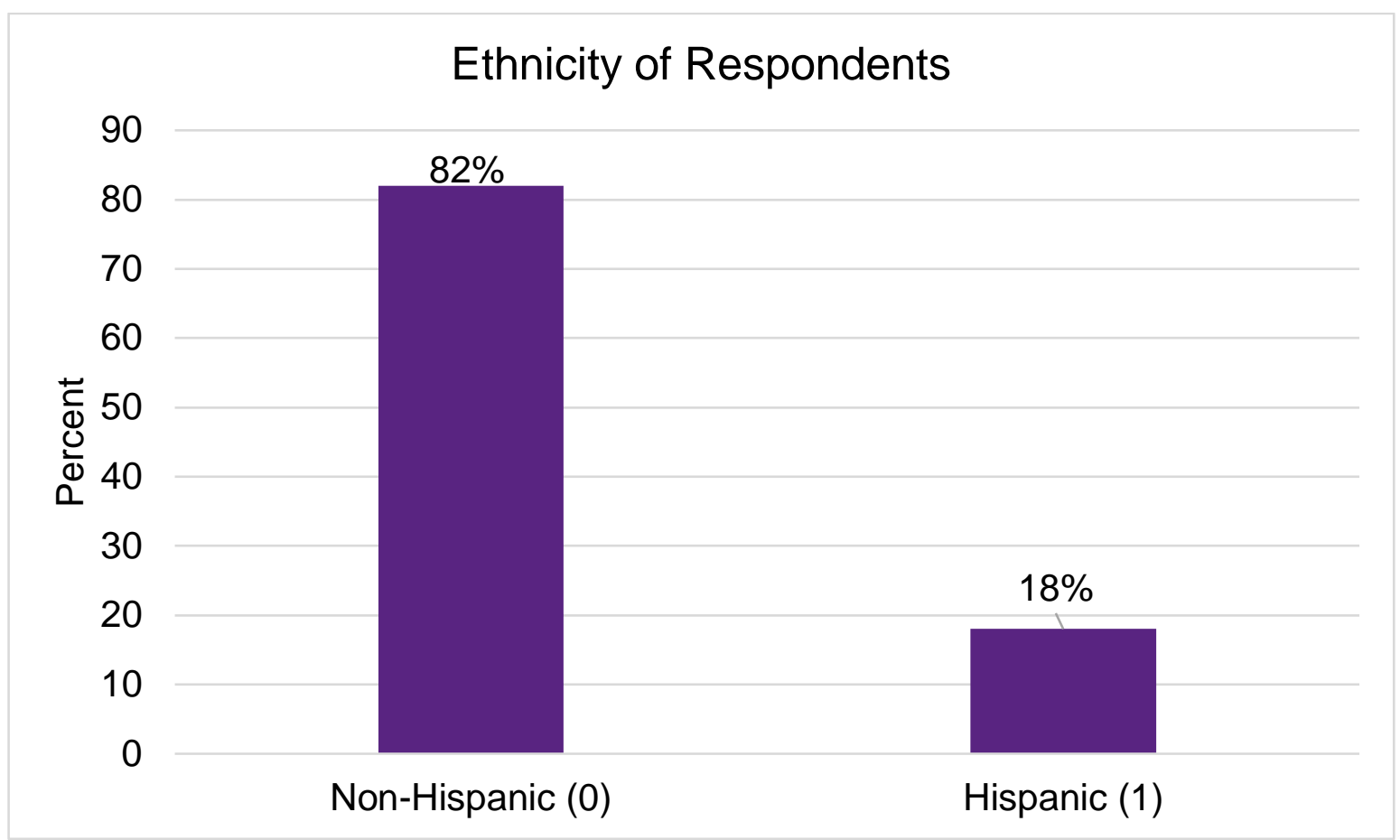

Figure 4. Frequencies for Ethnicity of Respondents 
MENTAL HEALTH AND FIRST GENERATION GRADUATES

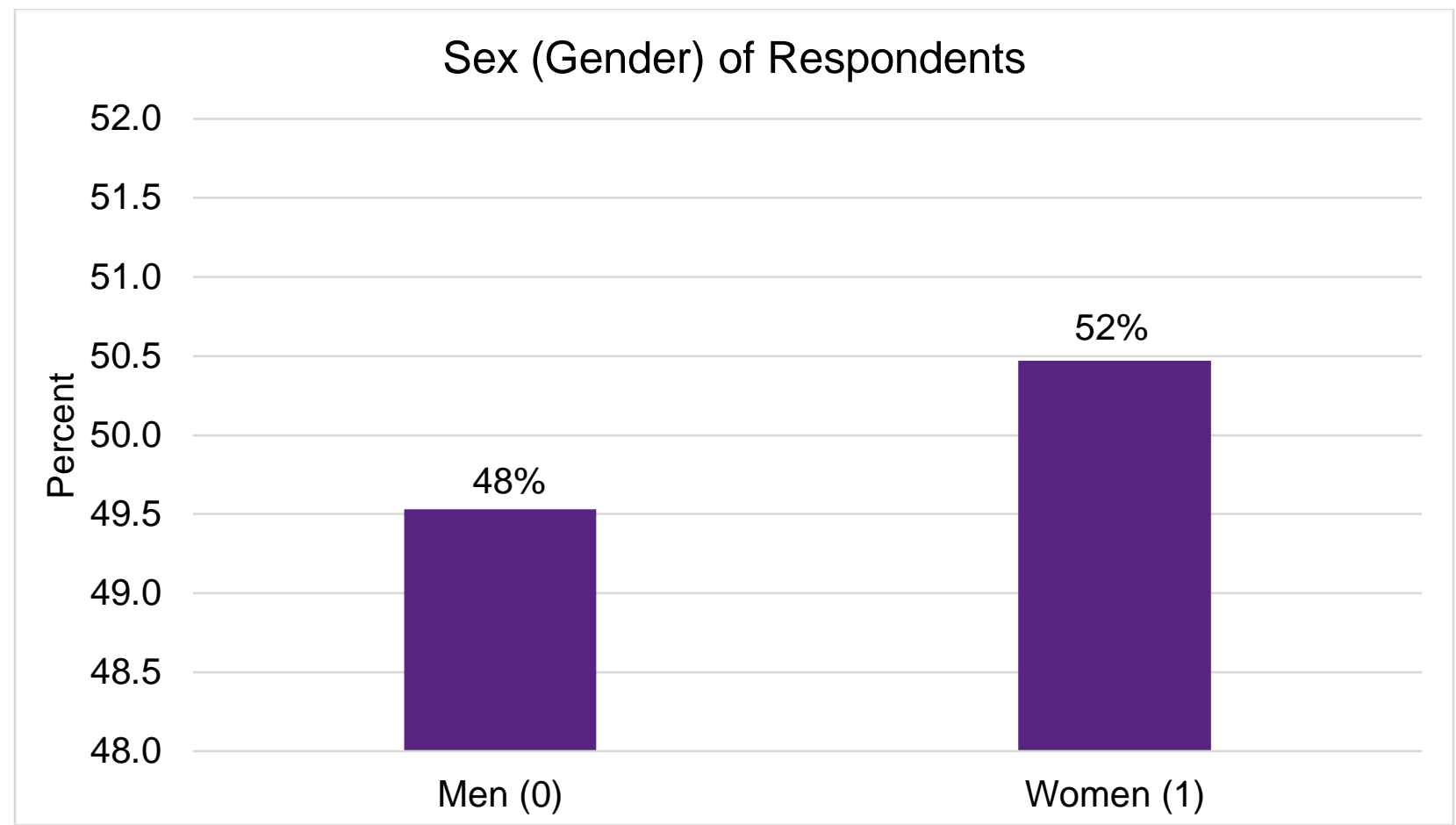

Figure 5. Frequencies for Sex of Respondents 
MENTAL HEALTH AND FIRST GENERATION GRADUATES

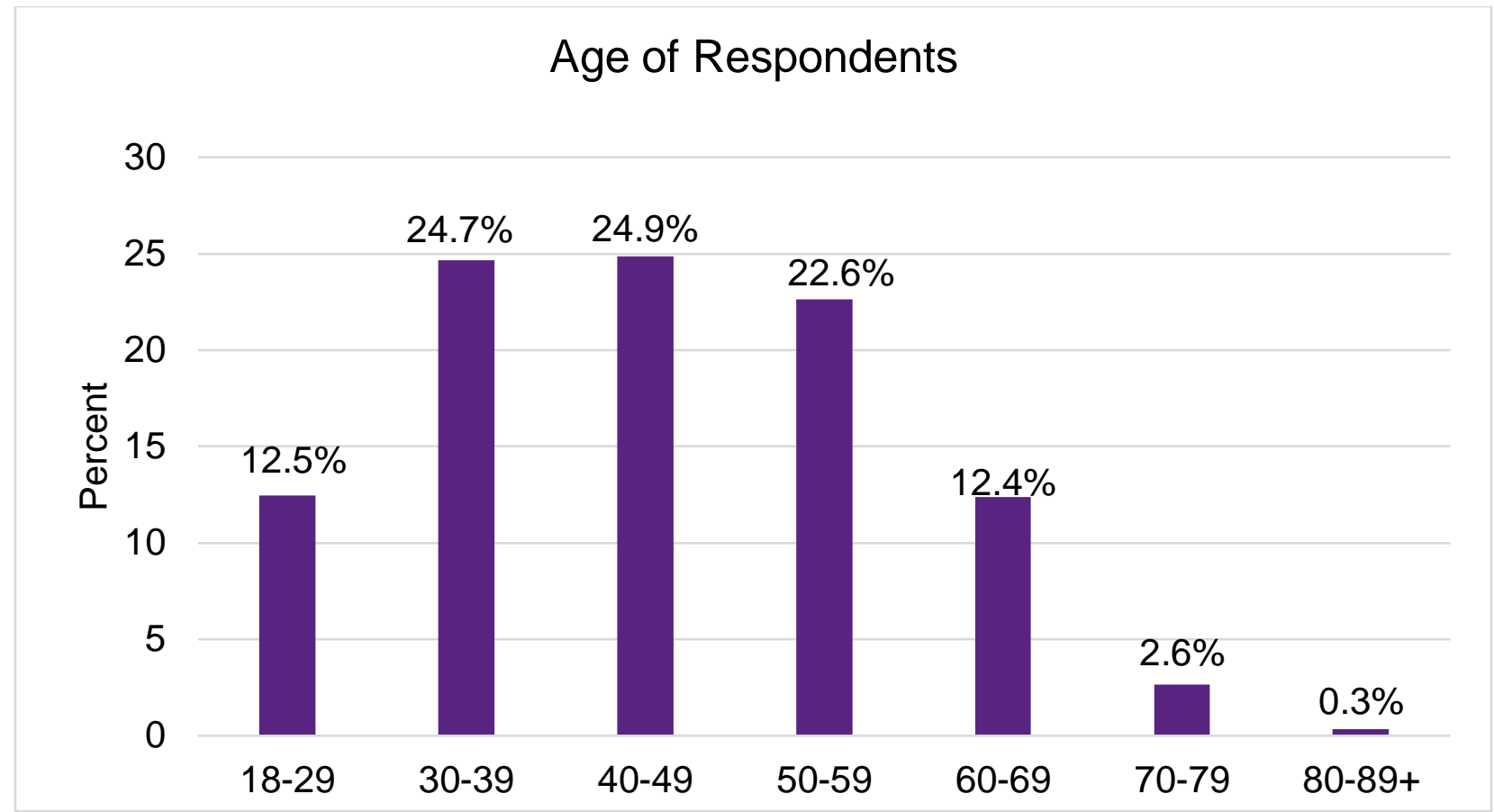

Figure 6. Age of Respondents 